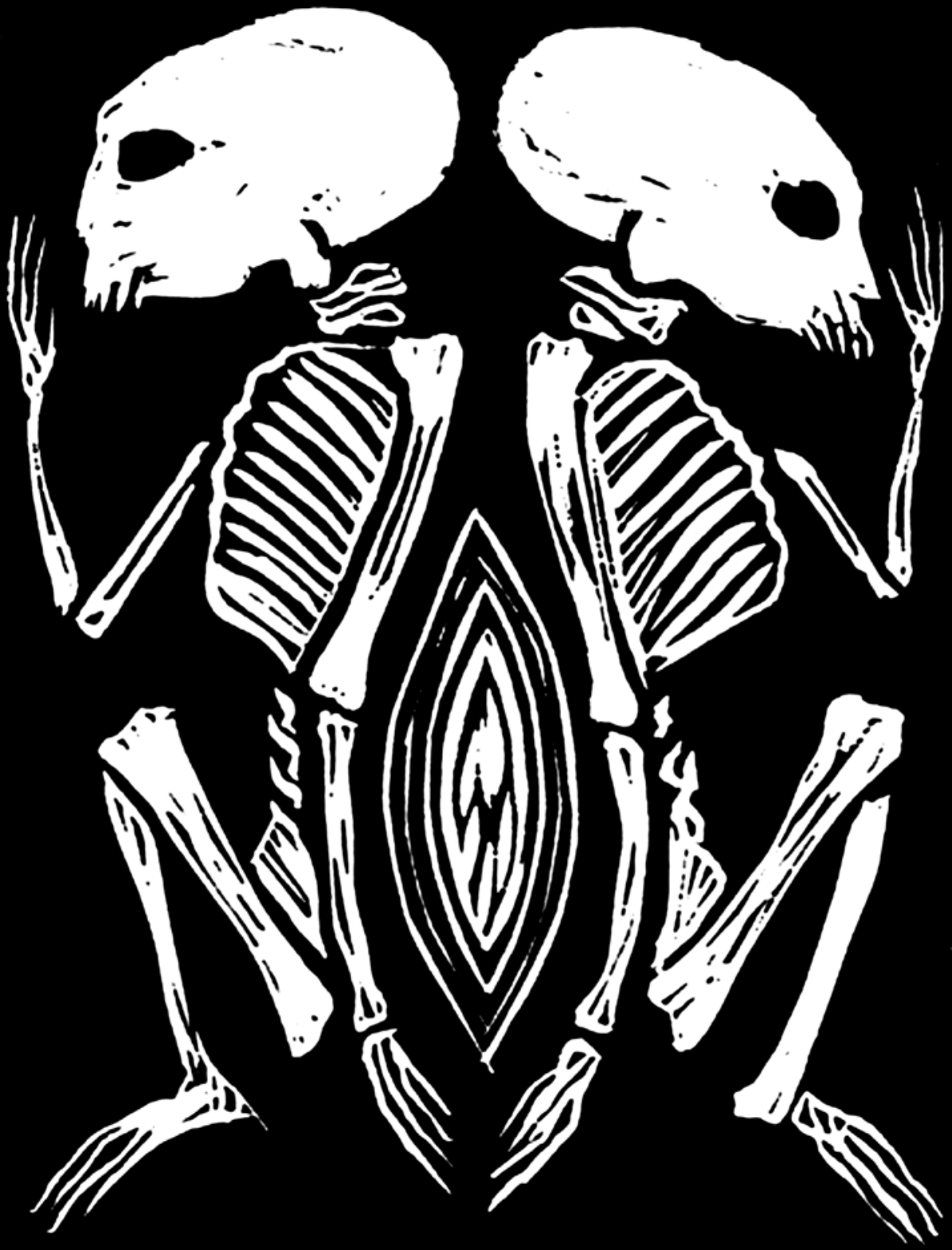




\title{
Grande Sertão: Veredas - da antropofagia ao canibalismo
}

\author{
Élide Valarini Oliver
}

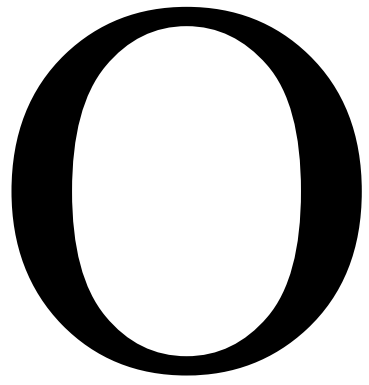

episódio de canibalismo em Grande Sertão: Veredas, longe de ser um detalhe acessório do mundo marginal e violento do jagunço, pelo contrário, carrega um valor hermenêutico crucial que toca no cerne das questões metafísicas levantadas na obra e, para além dela, convida ao enfrentamento crítico do conceito metafórico de Antropofagia avançado por alguns dos primeiros modernistas. O que é o ser humano? Não estaria a humorada antropofagia proposta pelo Manifesto Antropófago de Oswald de Andrade escondendo, em vez de revelar, os avessos da alma humana?

A ideia de atravessar o Liso do Suçuarão, de geografia ativamente hostil ao grupo de jagunços liderados por Medeiro Vaz, e que quase leva o grupo à morte, vem de Diadorim, que, cego/a de vingança pela morte do pai Joca Ramiro, busca um enfrentamento com os traidores que o assassinaram, dentre os quais Hermógenes, do qual se diz que tem um pacto com o diabo. Nada se sabe da relação entre Diadorim e Joca Ramiro. Não se sabe, igualmente, que é sua filha disfarçada.

\footnotetext{
1 Depois de morta na justa (indivíduo contra indivíduo), revela-se o segredo e o diabo se dissolve: Maria Deodorina, presente de Deus.
}

Diadorim, levando-os ao extremo da sobrevivência é, nesse momento, um presente do diabo (dia-doron ${ }^{1}$ ).

Nesse mundo dos avessos, a travessia do Liso, no relato-monólogo de Riobaldo, nos informa que os burros fogem com a carga toda de mantimentos, alguns homens morrem assim como muitos dos cavalos, e

"Só não acabamos sumidos dextraviados, por meio do regular das estrelas [...] os homens tramavam zuretados de fome - caça não achávamos - até que tombaram à bala um macaco vultoso, destrincharam, quartearam e estavam comendo. Provei. Diadorim não chegou a provar. Por quanto - juro ao senhor - enquanto estavam ainda mais assando e manducando, se soube, o corpudo não era bugio não, não achavam o rabo. Era homem humano, morador, um chamado José dos Alves! Mãe dele veio de aviso, chorando e explicando: era criaturo de Deus, que nu por falta de roupa... Isto é, tanto não, pois ela mesma ainda estava vestida com uns trapos; mas o filho também escapulia assim pelos matos por da cabeça prejudicado. Foi assombro. A mulher, fincada de joelhos, invocava. Algum disse: 'Agora, que

ÉLIDE VALARINI OLIVER é professora adjunta do Departamento de Espanhol e Português da Universidade da Califórnia e autora de Variações sob a Mesma Luz (Edusp). 
está bem falecido, se come o que alma não é, modo de não morrermos todos...' Não se achou graça. Não, mais não comeram, não puderam. Pra acompanhar, nem farinha não tinham. E eu lancei. Outros também vomitavam. A mulher rogava. Medeiro Vaz se prostrou, com febre, diversos perrengavam. - Aí, então, é a fome?" (Rosa, 1995, p. 40).

O episódio prossegue com os jagunços levando com eles a mulher e ela temendo que "faltasse outro de-comer e ela servisse" (p. 41). Por fim, "Matou-se capivara gorda [...]. Dum geralista roto, ganhamos farinha-de-buriti, sempre ajudava" (p. 41) e finalmente os jagunços encontram uma fazenda.

Embora o monólogo de Riobaldo, discurso limítrofe, seja concebido para ser apreciado levando-se em conta os quatro níveis implicados na fruição da obra literária segundo a literatura medieval, ou seja, os níveis literal, alegórico, tropológico e anagógico ${ }^{2}$, o relato aqui tende a concentrar-se e gerar sua força a partir do hediondo fato em si. O que define a questão do humano, no trecho, não se prende a nenhuma metafísica (muito pelo contrário, "se come o que alma não é") mas a uma observação baseada no mundo natural: "o corpudo não era bugio não, não achavam o rabo". O corpo do corpudo e não sua alma. A presença ou ausência de rabo.

E o que é o homem humano? A questão do rabo, paradoxalmente, é e ao mesmo tempo não é o que separa o homem humano do macaco. Sem rabo aparente, na ordem do mundo natural, tal como Darwin descreve em The Descent of Man:

"No homem, o osso do cóccix, junto com certas outras vértebras a partir daqui a serem descritas, embora sem função de cauda, claramente representa essa parte em outros animais vertebrados. Num primeiro estágio embriônico, ele está livre, e se projeta para além das extremidades inferiores; como pode ser visto no desenho (Figura 1) de um embrião humano. Mesmo depois do nascimento, sabe-se que em certos casos raros e anômalos, forma um pequeno e externo rudimento de cauda" (Darwin, 1952, p. 264) ${ }^{3}$.

Para Darwin, é a inclusão da espécie humana dentro da grande árvore de nossos antepassados hominídeos que importa observar e descrever. A questão do rabo é ainda mais enganadora. Não só os humanos ainda conservam um resto de cauda, como também os grandes macacos, assim como os humanos, não a têm. Como ele mesmo observa:

"Segundo uma popular impressão, a ausência de cauda é o que distingue eminentemente o homem; mas, como aqueles grandes macacos que lhe estão mais próximos são destituídos desse órgão, seu desaparecimento não se relaciona exclusivamente ao homem. A cauda muitas vezes difere de forma notável em comprimento dentro da mesma ordem: assim, em algumas espécies de macacus é mais longa que o próprio corpo, e é formada de vinte e quatro vértebras; em outros, consiste de um toco muito pouco visível, contendo apenas três ou quatro vértebras" (Darwin, 1952, p. 283) ${ }^{4}$.

Entretanto, no episódio de $G S V$ em questão, essa diferença ou semelhança gera opções de leitura extremamente dificultosas, pois se é o rabo, "popularmente", que serve para delimitar a fronteira entre mundo humano e mundo animal, como o próprio Darwin indica, esse desapareceu também nos grandes macacos. Como ficamos, então, com José dos Alves? Talvez seja franzino, baixo, uma inferência bastante lata, visto que o texto não avança nenhuma informação a esse respeito, pelo contrário, os jagunços "tombaram um macaco vultoso". Mas daí a confundi-lo com um macacus provido de cauda? Mesmo que primatas como chimpanzés, gorilas, orangotangos e bonobos não habitem o cerrado, os gerais e menos ainda o deserto do Liso do Suçuarão, ainda assim, o muriqui, ou mono-

2 Em sua introdução ao estudo da exegese medieval, Henri de Lubac (1961) cita o dístico estabelecido na Idade Média tardia relativo aos sentidos da sagrada escritura: "A letra ensina eventos, a alegoria, o que deves crer/ A moralidade ensina como deves agir, a anagogia, o que deves almejar".

3 Todas as traduções no texto e notas são da autora do artigo. No original: "In man, the os coccyx, together with certain other vertebrae hereafter to be described, though functionless as a tail, plainly represent this part in other vertebrate animals. At an early embryonic period it is free, and projects beyond the lower extremities; as may be seen in the drawing (fig1) of a human embryo. Even after birth it has been known, in certa rare and anomalous cases, to form a small external rudiment of a tail".

4 "According to a popular impression, the absence of a tail is eminently distinctive of man; but as those apes which come nearest to him are destitute of this organ, its disappearance does not relate exclusively to man. The tail often differs remarkably in length within the same genus: thus in some especies of Macacus it is longer than the whole body, and is formed of twenty-four vertebrae; in others it consists of a scarcely visible stump, contaning only three of four vertebrae". 
-carvoeiro, o maior primata do Brasil, está longe de ser vultoso ${ }^{5}$ e possui cauda. Mas não é nem esse o macaco escolhido por Guimarães Rosa, que cita o bugio. Este, além de ter cauda, tem porte médio, pesando por volta de sete quilos, e não poderia, tanto pelo porte, como pela cauda, ser confundido com José dos Alves. Seria a fome? A violência do grupo? Ou a soma de ambas? A fome é ao mesmo tempo animal e humana. Há procedimentos culturais que a transformam.

Entretanto, possuir cauda ou não, no caso, parece uma suspeita desculpa. Em que momento viram os jagunços que José dos Alves não a possuía? Se era bugio, a cauda seria aparente ainda vivo e mesmo de longe, ou será que esses jagunços nunca tinham visto bugios? O que causa espanto ao leitor é que, na narrativa, só depois de José dos Alves ter sido morto, cozido e comido é que os jagunços parecem notar-lhe a falta de cauda! Como foi que esse detalhe escapou ao grupo?

Igualmente perturbador é o fato de que José dos Alves, como todo humano, é bípede. E nisso difere fundamentalmente dos outros primatas e sobretudo dos bugios, que vivem no alto das árvores, de onde os humanoides desceram há muito tempo. O texto, entretanto, não oferece precisão a esse respeito e mesmo que a narrativa pertença a Riobaldo, sendo portanto passível de incongruências, silenciamentos, talvez censuras, optar pela pobre conclusão de que se trata de mais um caso de narrador não confiável é simplificar e evadir a questão.

Teriam os jagunços, premidos pela fome, cometido o crime e depois voltado atrás?

O mundo do jagunço é o da caça e do caçador. Mata-se, come-se. A natureza existe para servi-lo e, quando não o serve, ele a toma, assim como toma também a fazenda, esse microcosmo de civilização, de transmutação do mundo natural em humano. $\mathrm{O}$ jagunço usa e abusa dos frutos do mundo societal da produção humana que é a fazenda, onde a natureza se transforma, da mandioca à farinha, da fruta ao doce, da carne à carne seca e, mesmo nas regiões mais desprovidas, do buriti à farinha-de-buriti. O jagunço saqueia a fazenda como usa da natureza.

Apenas em Riobaldo há ambivalência com relação ao ambiente natural que rodeia o mundo humano dos jagunços. É Diadorim quem ensina a Riobaldo a observar a beleza da natureza que os rodeia, simbolizada pelo pássaro manuelzinho-da-crôa. E Riobaldo nem jagunço era, tragado que foi para dentro desse mundo sem fundo, por amor.
Essa posição existencial, inconsciente e ironicamente naturalizada demonstra um abismo ainda maior e paradoxal, pois a violência e o saque dos jagunços são, apenas em aparência, atribuíveis moralmente ao mundo "animal". Na verdade, são é produto do humano, da lei, e dos fora da lei; dos incluídos e dos excluídos. E as leis dos fora da lei podem ser terríveis.

Ao mesmo tempo esse episódio de canibalismo marca a separação entre homem e natureza de maneira irônica, visto que o canibalismo em outras espécies animais é raro ${ }^{6}$. Está presente na espécie humana e, como se viu, em primatas próximos evolucionariamente a ela. Ian Tattersall relata que o enorme grupo de ossos encontrados no sítio de Gran Dolina, na Espanha, fósseis de uma linhagem de nossos antepassados comuns, que levou ao Homo neanderthalensis e ao Homo sapiens, mostra evidência de canibalismo. Os ossos fósseis, seja de humanos e de não humanos, foram tratados da mesma maneira, mostrando marcas de raspagem, cortes, talhos, fraturas, que demonstram que foram mortos para comer. Ainda mais importante é o detalhe de que: "Nenhuma evidência de tratamento especial ou ritual com respeito aos restos humanos foi encontrada"(Tattersall, 2012, p. 153). Seriam a nossa aversão e nosso tabu a fonte de uma reação profunda ao que foi uma inclinação ${ }^{7}$ ?

50 muriqui ou mono-carvoeiro chega a medir 1,5 $\mathrm{m}$ de altura e a pesar $15 \mathrm{~kg}$ e possui uma cauda de $1,5 \mathrm{~m}$.

60 dragão-de-komodo é uma delas. Outros exemplos, em geral, envolvem situações extremas, tal como o grupo de jagunços em questão.

7 Sabe-se que uma variante fatal da doença de CreutzfeldtJakob é passada adiante por canibalismo, dentre as quais a kuru, prevalente entre as tribos de Papua, Nova Guiné, que até recentemente praticavam canibalismo. Cabe ressaltar, entretanto, que a busca de evidência dessa prática dos hominídeos no passado, baseada exclusivamente no comportamento atual dos chimpanzés é problemática. A separação entre os assim chamados hominídeos e os chimpanzés ocorreu por volta de seis milhões de anos atrás e não há evidências até o momento que justifiquem uma atribuição por analogia, como o faz a psicologia evolucionista, comparando primatas aos humanos da atualidade. Isso, por outro lado, não invalida a tese darwiniana de que não há separação radical entre a espécie humana (criada "especialmente") e as outras espécies animais. Não se trata de afirmar que o ser humano é o "único" que possui linguagem ou uso de ferramentas, mas sim que essa linguagem é complexa e simbólica, e que o uso de ferramentas igualmente se sofisticou. As diferenças entre o ser humano e os outros animais seriam fundamentalmente de grau, o que também não implica que a partir daí não se tornem substantivas, tal como a linguagem simbólica. 
Aprofundando um pouco além essa possibilidade, não estariam esses jagunços famintos e com medo da morte dispostos, consciente ou inconscientemente, a confundir José dos Alves com um bugio? O impedimento do tabu, sem dúvida, se faz claro: alguns vomitam. Mas o comentário de um deles, "agora, que está bem falecido, se come o que alma não é, modo de não morrermos todos", deixa pensar. Depois de morto, sem a alma, come-se o corpo. É o contrário do banquete antropófago, que come o corpo para adquirir a "alma", aqui não no sentido cristão, mas algo perto de seu sentido etimológico, anima, o que anima, respira, seu poder, seu daimon. Não é sem motivo que os reformados - como Jean de Léry -, escrevendo sobre o ritual antropofágico, relacionaram-no à eucaristia católica. A insistência na transubstanciação do pão e do vinho em corpo e sangue de Cristo, que revivifica e faz ressuscitar, encontra, na crítica dos reformados, e com Jean de Léry (1994), etnólogo e antropólogo avant la lettre, um potente paralelo8.

Se há distanciamento entre o humano e o animal em $G S V$, o episódio de canibalismo, entretanto, parece inverter e subverter essa distância. O humano se faz animal ao comer o animal que se revela humano. Nesse breve momento de horror, estão atuando as duas partes do animal humano, a que se civilizou, respondendo ao canibalismo, com a criação do tabu, com uma recusa; e a que volta ao animal humano instintual $^{9}$, mesmo que, nesse caso, "inconscientemente". Teriam os jagunços ao menos reconhecido em José dos Alves um semelhante, ou era tanta a fome que, ao avistá-lo, viram-lhe somente a parte animal? Sintomaticamente, a mãe de José dos Alves tem medo de que o grupo a leve consigo para devorá-la.

Aliás, o próprio assassinato de José dos Alves não se apresenta, em nenhum momento, como uma questão moral para o grupo, que gosta de se distinguir como pertencente às hostes do bem, em luta contra os traiçoeiros e pactários do mal ${ }^{10}$. Será, entretanto, o próprio narrador que, ao se tornar chefe do bando, enveredará pelos caminhos do mal acreditando-se vendedor de sua alma ao diabo. É, pois, esse grupo identificado com o bem que, ao tomar consciência da humanidade do animal que mataram e comeram, segue adiante levando consigo a mãe do morto, que os teme.

José dos Alves não pode defender-se do grupo, pois é da cabeça prejudicado. Uma das formas mais tradicionais de defesa da posição de separação entre o homem e o animal é a capacidade daquele de articu- lação simbólica. Segundo a escolástica medieval, de inspiração aristotélica, a capacidade de julgamento e a de pensamento eram atributos da alma. Mas, se a alma de José dos Alves já não está junto ao corpo, o que se faz dessa cabeça prejudicada? Emitiria ele ruídos em vez de palavras?

Os paradigmas de separação entre homem e animal mudam a cada vez que são encontrados, no mundo animal, exemplos concretos de continuidade e gradação entre as espécies: pensamento, julgamento, instrumento, racionalidade, capacidade simbólica, autoconsciência, etc.

A cada objeção às descobertas de Darwin com relação ao mundo humano e animal em continuidade e grau e não em barreira inseparável, até mesmo o

8 Ver sobretudo o capítulo VI, onde Léry (1994, p. 177), calvinista, discute a transubstanciação dos católicos e a consubstanciação, defendida pelos luteranos. Condenando os católicos, Léry os aproxima dos goitacases: "ils vouloyent neantmoins non seulement grossierement, plustost que spirituellement, manger la chair de Jesus Christ, mais qui pis estoit, à la maniere des sauvages nommez Ou-ëtacas, dont j'ay parlé ci-devant, ils la vouloyent mascher et avaler toute crue" ("queriam, no entanto, não somente grosseiramente, mais que espiritualmente, comer a carne de Jesus Cristo, mas do pior jeito, à maneira dos selvagens chamados goitacases, dos quais falei acima, eles a queriam mastigar e engolir toda crua"). Léry aproxima assim católicos dos goitacases, mas notando que os primeiros são piores. Os tupinambás e outras tribos do ramo tupi comiam a carne humana assada. Os goitacases, "comme chiens et loups" (Léry, 1994, p. 153), entretanto, a comiam crua, o que representaria o grau supremo de selvageria; e, como o texto implica, os católicos seriam piores, por serem supostamente civilizados, diferentemente dos goitacases, que aliás eram vistos como selvagens pelos grupos tupis. A esse respeito ver, também, Lestringant (1982). Outro paralelo perturbador pode ser encontrado no famoso caso do acidente aéreo nos Andes, em 1972, cujos sobreviventes comeram os passageiros mortos. Nesse caso, comeram os que já estavam mortos, diferentemente de José dos Alves, que foi morto para esse fim. A questão do assassinato deste, como dito acima, jamais se coloca como questão moral para o grupo dos jagunços.

9 Há prova documental filmada em que chimpanzés são vistos perseguindo, caçando e matando macacos e comendo-os. Outros documentários filmaram chimpanzés devorando outros chimpanzés, ou seja, animais de sua mesma espécie. Grupos de chimpanzés também entram em guerra uns com os outros. Bonobos, vistos erroneamente como pacíficos, quando estudados em seu ambiente natural (e não em zoológicos), também têm comportamento semelhante. Ver por exemplo, na série Planet Earth da BBC, com comentários do naturalista Sir David Attenborough, o ataque canibal. Também o vídeo da National Geographic, Among the wild Chimpanzees, com a primatologista Jane Goodall, traz exemplos de canibalismo e guerra.

10 Lembre-se o episódio do julgamento de Zé Bebelo, que constitui o clímax do livro. 
próprio autor, já no século XIX, opunha exemplos demonstrativos. Escrevendo a respeito da "suposta barreira intransponível entre as mentes humanas e a dos animais inferiores", Darwin (1952, p. 294) cita em nota Leslie Stephen em artigo escrito em 1873 em defesa de sua posição. A crítica de Stephen ainda é pertinente:

"As distinções que têm sido feitas nos parecem estar sustentadas em fundações que não são melhores do que um grande número de outras distinções metafísicas: a saber, a suposição de que, porque se pode dar nomes diferentes a duas coisas, elas devem, portanto, ter naturezas diferentes. É difícil entender como alguém que alguma vez já teve um cachorro ou que já viu um elefante possa ter alguma dúvida do poder que um animal tem de cumprir os procedimentos essenciais de raciocínio" (Stephen apud Darwin, 1952, p. 294) ${ }^{11}$.

A antropologia, não há muito tempo atrás, propunha que apenas o animal humano pode usar ferramentas e linguagem. No entanto, a evidência de que ambas essas capacidades estão presentes em vários animais fez recuar, ainda mais uma vez, os pressupostos de separação radical, que são, afinal, uma herança de fundo religioso, visto que é a Bíblia que fornece o paradigma mais radical dessa separação quando a divindade ali delega a Adão o poder de dar nomes aos animais ${ }^{12}$, o que é, em geral, interpretado, como a prova de uma hierarquia de poder do humano sobre o resto da natureza.

Outro ponto igualmente divisor é a capacidade de raciocínio, que também tem uma longa presença na história da filosofia e da ciência como definidora do humano.

São significativas as críticas a essa posição. Swift, em carta a Pope, ironiza a suposta racionalidade hu-

11 Darwin cita Leslie Stephen (pai de Virginia Wolf) em nota à pagina 294. Ele escreve na nota: "I'm glad to find that so acute a reasoner as Mr. Leslie Stephen ('Darwinism and Divinity', Essays on Free Thinking, 1873, p. 80), in speaking of the supposed impassable barrier between the minds of man and the lower animals says, 'The distinctions, indeed, which have been drawn, seem to us to rest upon no better foundation than a great many other metaphysical distinctions; that is, the assumption that because you can give two things different names, they must therefore have different natures. It is difficult to understand how anybody who has ever kept a dog, or seen an elephant, can have any doubt as to an animal's power of performing the essential processes of reasoning'". mana tornando famosa a dicotomia entre animal racional e animal capaz de usar a razão. A primeira formulação pressupõe que a definição essencial do humano é a racionalidade ${ }^{13}$. A segunda admite que capacidade não implica definição, mas eventualidade. Não é necessária, mas contingente ${ }^{14}$.

Por outro lado, Darwin (1952, p. 294), a esse respeito, relata o seguinte:

"Vou concluir citando uma observação feita pelo ilustre Humboldt. 'Os arrieiros na América do Sul dizem «Não vou lhe dar a mula cujo andar é o mais fácil, mas la mas racional - a que raciocina melhor»'; e acrescenta: 'essa expressão popular, ditada por longa experiência, combate o sistema de máquinas animadas

12 "Tendo, pois, o Senhor Deus formado da terra todos os animais dos campos, e todas as aves dos céus, levou-os ao homem, para ver como ele os havia de chamar, e todo o nome que o homem pôs aos animais vivos, esse é o seu verdadeiro nome" (Gênesis, 2, 18-19)

13 Tattersal, loc. cit, a respeito da racionalidade humana comenta: "we are most certainly not entirely rational beings; a point that should need no belaboring to any observer of our species. One major reason for this is that, through the vagaries of a long and eventful evolutionary history, some of the newest components of our brains - those strange, complex organs in our heads that govern our behaviour and experiencecommunicate with each other via some very ancient structures indeed" (xv). Segundo o paleoantropólogo, portanto, os novos componentes do cérebro que governam nosso comportamento e experiência, por exemplo, por causa de nossa longa história evolucionária, se comunicariam um com o outro através de estruturas muito antigas, o que certamente acaba em dissonância.

14 Jonathan Swift (s. d.), em carta de 29 de setembro de 1725 a Alexander Pope: "But principally I hate and detest that animal called man, although I heartily love John, Peter, Thomas, and so forth. This is the system upon which I have governed myself many years, but do not tell, and so I shall go on till I have done with them. I have got materials toward a treatise, proving the falsity of that definition animal rationale, and to show it would be only rationis capax. Upon this great foundation of misanthropy, though not in Timon's manner, the whole building of my Travels is erected; and I never will have peace of mind till all honest men are of my opinion" ("Mas principalmente odeio e detesto aquele animal chamado homem, embora ame de todo o coração John, Peter, Thomas, e assim por diante. Este é o sistema pelo qual me governo há muitos anos, mas não diga a ninguém, pois assim continuarei até que tenha acabado com eles. Tenho material para um tratado, provando a falsidade daquela definição animal rationale, e para mostrar que seria apenas rationis capax. Sobre essa grande fundação misantrópica, embora não à maneira de Timon, o inteiro edifício de minhas Viagens está erigido; e nunca terei paz de espírito até que todos os homens honestos sejam de minha opinião"). 
melhor, talvez, do que todos os argumentos da filosofia especulativa"” (Swift, s. d.) ${ }^{15}$.

Estar da cabeça prejudicado é estar, portanto, abaixo do mundo humano. É pertencer já à esfera inferior do mundo animal, pois a capacidade de raciocínio, julgamento, etc., que formam, no entender dos teólogos, a alma, e, no entender dos filósofos, a essencialidade da condição humana, não está presente. Disso, até mesmo o jagunço sabe, visto que corpo, sem alma, se pode comer.

Mas o impedimento natural não se oculta em categorias abstratas. José dos Alves não tinha rabo. Era, portanto, humano. Mas era o humano marginal: pobre, nu.

A roupa também define o ser humano, e a mãe de José dos Alves, sob esse ponto de vista, corre perigo, pois ela também, por ser pobre, está apenas vestida com uns trapos. Estaria, assim, a um passo de ser devorada?

As balizas que sinalizam os limites entre o mundo natural e o mundo humano, para os jagunços, que também vivem num mundo à parte, marginal, se fazem mais movediças ainda, movidos que são pela fome e pelo medo da morte.

A obra de João Guimarães Rosa oferece ainda outros exemplos de seres marginais, limítrofes, que vivem entre o mundo humano e animal, nos confins da Fazenda, símbolo da civilização, e a amplidão do mato. Em Meu Tio, o Iauaretê, outro monólogo, o narrador humano passa para o lado animal, o jaguar, e investido desse totem misterioso, passa a matar e a comer gente, e dentre essa gente, sobretudo os pretos ${ }^{16}$. Ainda em GSV, os sugestivamente chamados Catrumanos também vivem à parte, estranhos, diferentes. A antiga ordem dos assim chamados quadrúmana se compõe de animais tais como lêmures e outros tipos de macacos que têm pés e mãos igualmente preênseis. Vemos aqui deslocada a questão entre humanos bípedes e macacos quadrúmanos, catrumanos. Num mundo de valentias humanas, sejam elas de jagunços ou teólogos, os quatro-mãos, quadrúmana, catrumanos, não são manos, irmãos, mas uma espécie à parte, quase-humanos. Mas, cuidado, é no mundo humano que se metem os pés pelas mãos, com rabo ou não. Um mundo do avesso.

Um nexo que nos parece igualmente central nesse episódio de canibalismo nu e cru é, finalmente, o olhar irônico, proposital ou não, que lança ao modernismo de 1928 com seu Manifesto Antropófago. Adotado como identidade puramente eletiva, produto, afinal, de um movimento cultural europeizado, com pouco ou nada do elemento indígena, mas ansioso por elaborar-se ou mimetizar-se miscigenado a ele, sua proposição de tomar o lado do antropófago e comer a alma do Europeu levanta muitas questões. É produto de uma refinada idealização aliada a uma profunda crise de identidade: quem somos, os brasileiros?

A antropofagia resulta, ironicamente, num positivismo comtiano. Ao pretender, por exemplo, trocar o catolicismo português pela celebração do banquete antropófago, a emenda não deixa de lembrar Comte, que queria substituir a religião pelo culto à razão ao fundar o seu Templo da Humanidade ${ }^{17}$. Uma consequência inesperada dessa proposição é que esse era justamente, afinal de contas, o ponto nevrálgico da crítica dos calvinistas ao próprio catolicismo, que julgavam canibal, como apontamos em nota abaixo. Mas certamente não podemos negar ao Manifesto o impacto e nem o humor.

Entretanto, escrevendo com a distância de quase trinta anos, João Guimarães Rosa em $G S V$ teve tempo suficiente para refletir sobre as diferenças e dessemelhanças entre canibal e antropófago em sua obra. Sua recusa está em não romantizar e nem idealizar o último em detrimento dos fundos da alma do primeiro. Os resquícios do nobre selvagem, a despeito de toda a capa antropófaga que lhe quer dar Oswald de Andrade, não podem sobreviver no mundo complexo, mutante, limítrofe da obra rosiana. Talvez o próprio autor não estivesse plenamente cônscio, mas certamente respondeu, em sua obra, à adoção alegre e positivista do Modernismo Antropófago. O episódio em GSV pode ser interpretado como uma poderosa reflexão crítica à adoção de identidades culturais idealistas, quando não contraditórias. Parece-nos uma revisão sem máscaras

15 "I will conclude by quoting a remark by the illustrious Humboldt. 'The muleteers in S. America say, "I will not give you the mule whose step is easiest, but la mas racional, - the one that reasons best ", and he adds, 'this popular expression, dictated by long experience, combats the system of animated machines, better perhaps than all the arguments of speculative philosophy'."

16 A esse respeito, ver nosso artigo sobre o assunto (Oliver, 2008).

17 A religião positivista ainda possui um templo no Rio de Janeiro, e em 1903 os positivistas brasileiros fundaram o único Templo da Humanidade ainda operante em Paris: 5, rue Payenne. 
à Antropofagia metafórica, porque oferece sua contrametade literal como prova de sua impossibilidade. O canibalismo em $G S V$ é a anatomia lúcida de sua festiva contraparte antropofágica, ou seja, a disseminação e a diluição "benigna" do conceito; afinal, o ser antropófago é tudo menos "antropofágico". O símbolo cultural é, como toda idealização, composto de partes escolhidas. $G S V$ o obriga a comer-se a si próprio e a vomitar-se em seguida.

Voltando aos quatro níveis de interpretação escritural da Idade Média, podemos nos perguntar qual o papel desse episódio na cosmologia do GSV?

$\mathrm{O}$ entrelaçamento do mundo moral e anagógico aponta para uma crise, uma ruptura entre o mundo da natureza e o mundo humano. Ao negar a continui- dade entre ordem natural e ordem humana, a moral teológica se propõe a combater o mal (que encontra no darwinismo). Mas, nessa luta entre o bem e o mal, Riobaldo acreditou-se pactário. O mundo dos jagunços, mesmo vomitando a carne humana, requer uma violência de outra ordem, diferente do simples matar para não morrer de fome do mundo natural. Se nisso encontramos precedente em nossos ancestrais, provavelmente canibais, ou nos primatas nossos parentes - tal como o narrador de Meu Tio, o Iauretê, que era parente do jaguar -, é porque, mesmo cientes de nossa ordem no mundo natural, mesmo como jagunços habitando um mundo limítrofe, marginal, temos que dar conta da difícil jornada de nos transformarmos em humanos. Travessia.

\section{BIBLIOGRAFIA}

DARWIN, Charles. The Descent of Man and Selection in Relation to Sex. Chicago, University of Chicago Press, 1952.

LÉRY, Jean de. "Catholiques et Cannibales: le Thème du Cannibalisme dans le Discours Protestant au Temps des Guerres de Religion", in Pratiques et Discours Alimentaires à la Renaissance. Paris, Maisonnneuve et Larose, 1982.

LÉRY, Jean de. Histoire d'un Voyage Faict en la Terre do Brésil. Paris, Le Livre de Poche, 1994.

LESTRINGANT, Franklin. "Catholiques et Cannibales: le Thème du Cannibalisme Dans le Discours Protestant au Temps des Guerres de Religion", in Pratiques et Discours Alimentaires à la Renaissance. Paris, Maisonnneuve et Larose, 1982, pp. 233-45.

LUBAC, Henri de. Exégèse Médiévale: les Quatre Sens de l'Écriture. Vol 1. Paris, Aubier, 1961.

OLIVER, Élide Valarini. "Queneau's Poissons and Rosa's Jaguar. Two Literary Contributions on Animal and Human Condition", in Mosaic Journal for the interdisciplinary study of literature, vol. 41, n. 4, Canada, December 2008, pp. 129-42.

ROSA, João Guimarães. Grande Sertão: Veredas. Em Obras Completas. Vol. 2. Rio de Janeiro, Aguilar, 1995.

SWIFT, Jonathan. The Correspondence of Jonathan Swift. Disponível em: http://www.ourcivilisation. com/smartboard/shop/swift/letters/index.htm.

TATTERSAL, Ian. Masters of the Planet. London, Palgrave Macmilla, 2012. 